\title{
Perception of Digital Media Training in Selected Universities in Kenya
}

\section{Silahs Chemwaina*}

Moi University, Eldoret, Kenya

\begin{abstract}
Journalism education and training is changing due to the rapidly evolving information communication technologies. These technological developments have transformed the media environment leading to new ways of communication. As a result, there has been concern about the impact of digital technologies and consequently, appropriateness of journalism training in Kenya. The purpose of the study was therefore to establish the perception of digital media training in four selected universities in Kenya. The study was guided by the diffusion of innovation theory which highlights the need for learners to acquire appropriate knowledge for the purposes of employment and career development. The study adopted a survey research design targeting a total population of 223. Mixed research approach with quantitative as well as qualitative techniques was used in the study. The findings show that the study digital media training is essential in giving hands on training to graduates and empowers them with adequate competencies and skills that they can use in the market such as in the process of collecting, processing and packaging news in the right way. The findings also revealed that journalism programs are too conceptual and spend little time on practical journalistic skills such as online reporting, computer applications, digital editing among other courses. Time spent on theory classes especially in teaching practical oriented courses is not useful for the daily lives of journalists. It is recommended that universities should review journalism training and integrate their curricula with digital media courses required by the market. Furthermore, the study recommends that journalism departments need to identify and provide resources that enhance the quality of digital media training.
\end{abstract}

Keywords: Digital media; Training; Curricula; Journalism; New media; Convergence

\section{Introduction}

Digital media technology is rapidly evolving as are the practices of mass communication, including media production and distribution. As a communication medium, digital media now rivals print and broadcast media. Professionals in journalism and mass communication are therefore confronted by the need to acquire the knowledge and skills required by this new and still evolving media landscape.

Digital media are emerging technologies used in gathering, processing and disseminating information. The technologies have had great impact on print broadcast media especially in making them accessible online. Digital media in this context of the study is an academic training of journalism which incorporates practical training that prepares trainees to work in a converged newsroom environment.

Digital media and convergence is an ongoing process, occurring at various intersections of media technologies, industries, content and audiences; it is not an end state. Due to the proliferation of channels and the increasingly ubiquitous nature of computing and communications, we are entering an era where media will be everywhere, and we will use all kinds of media in relation to one another.

In the wake of modern communication technologies, there is need for journalists to develop new skills for gathering, processing and managing information, new structures for transmitting information across different channels, and new creative genres to exploit the potentials of those emerging information structures.

Universities providing journalism courses have been adopting emerging technologies, taking into consideration social, political and economic demands. Burgh [1] identified social, institutional and training challenges affecting the journalism practices. Consequentially, there is need to ensure that necessary skills are acquired by students in order to adapt to these changes.

\section{Journalism training and digital media}

New interactive features of hypertext, multimedia and social media platforms demand new journalistic knowledge and skills that go beyond the traditional skills [2]. The needs for media professionals to use digital media to moderate discussions, interact with the public or work with multimedia are becoming more and more important. Journalism training should therefore be up-to-date with emerging trends; consequently, universities have to embrace new technological avenues.

According to Carpenter [3], theoretical knowledge, basic writing and communication skills still remain top requirements in the era of digital convergence, but employers require journalism graduates to have knowledge and skills required in web content creation, multiplatform adaptability, and social media. Consequently, journalism programmes in universities have should be reviewed to incorporate digital media aspects for the purpose of enhancing digital media competency in their students.

Digital media knowledge and skills, especially in multimedia, hypermedia, new media, social media, web based and online media technologies, are becoming essential for effective news reporting and career development and growth. In addition, Nyabuga and Booker [4] agree that digital technologies have changed the working habits of journalists in Kenya. Today, journalists working in the newsrooms are expected to be multi-skilled in reporting on different platforms.

${ }^{*}$ Corresponding author: Silahs Chemwaina, Masters Student, Moi University, Eldoret, Kenya, Tel: +254 53 43363; E-mail: chemwaina@gmail.com

Received September 01, 2017; Accepted November 07, 2017; Published November 13, 2017

Citation: Chemwaina S (2017) Perception of Digital Media Training in Selected Universities in Kenya. J Mass Communicat Journalism 7: 353. doi: 10.4172/21657912.1000353

Copyright: ( 2017 Chemwaina S. This is an open-access article distributed under the terms of the Creative Commons Attribution License, which permits unrestricted use, distribution, and reproduction in any medium, provided the original author and source are credited. 
Consequently, journalism training needs to consolidate digital media concepts, knowledge, skills and proficiency into core competencies needed in work delivery using different new media platform effectively. Hall [5] argues that journalism training should integrate digital media knowledge and skills because the upsurge of the internet and associated technologies are increasingly defining the role of a media professional. Ugangu [6] observes that the internet has transformed the way news and other media programmes are sourced, gathered, and transmitted to mass audiences in Kenya.

\section{Theoretical Framework}

This study adopted the diffusion of innovation theory [7]. Diffusion of innovation theory is widely used in various disciplines such as: journalism, ICT among others to explain aspects of adoption of innovative products and services. Diffusion of innovation theory is the process by which an innovation in the form of new ideas, practices or products and services is adopted and communicated through certain channels over time among the members of a social system, society or community [7].

Diffusion of innovation theory is primarily concerned with the integration, adoption and communication of new ideas in a society or community. The theory is built on the premise that new ideas have perceivable channels, time and mode of being adopted by individuals or organizations based on various elements or attributes. Multiple authors highlight various elements of the diffusion of innovation theory $[7,8]$. The theory states that various aspects make the theory complete such as innovation, communication channels, time, social system, organizational structure, leadership, and innovative decisions in the organization. Innovation is an idea, practice or object that is perceived as new by the members of a social system.

\section{Incorporating digital media in journalism education}

Initially, media education was focused on the mass media (print, radio, film and television). With the development of ICT, interest moved on to digital media. In recent times, interest has been shared between mass media and digital media and is based around concern for the new digital environment, including both digital and new media.

Nevertheless, in Europe, it is still the norm to separate skills related to media education and digital skills. The former has a more critical component, and the latter, a more instrumental component. There are few curricula, formal or for lifelong learning, based on the convergence between media education and digital literacy. If, despite everything, the convergence takes place, it is more down to changes in technology and an integration of the media in a new communicative environment, than a theoretical discussion or disciplinary change.

The objective of the new digital media education is to prepare students for excellence in their professions. With a view to achieving the object of quality media education, universities in Kenya are in dire need of reconfiguring and updating their curricula to produce graduates who are prepared for excellent professional performance and leadership roles in the media and communication industry. Consequently, it is necessary to provide students with strong core content in critical thinking, research and analysis, information gathering, writing, graphics and design, and law and ethics as well as media technologies and skills.

Deuze [2] asserts that media education should focus on the best practices of teaching, both theory and practical skills, including cultural and critical reflective didactics. Students must not only be made to learn how to write; but also be taught how to think or rather how to reflect critically, analyze, interpret and move beyond basic reportage to the heart of journalism as watchdog.

\section{Infrastructure in journalism departments}

A well-equipped and adequate media laboratory is important where students can be able to learn digital media practically. Journalism departments are required to have an optimum number of computers and other resources which are proportionate to the number of students. Computers in the media laboratory should cater for audio and video editing, graphics design for production of magazines, newsletters and newspapers.

UNESCO [9] recommends that training materials in radio and television as well as computer equipment need to be increased and brought up to date so that media programmes are able to facilitate teaching and learning. Sufficient infrastructure for the journalism programmes should consist of networked computer hardware, modems, local area networks, intranets or campus wide backbone connecting LANs and multi-campus networks.

Houston [10] argues that students should have access to equipment and supportive resources for practical use and demonstration. Accessibility of resources could be measured in terms of computer to student ratio, departmental access to internet, supporting ICT infrastructures including reliable electricity supply with a standby uninterrupted power supply (UPS) system, among others. It is important that the laboratories should have modern computers installed with updated programs which reflect what is on-going in the journalism environment.

\section{Material and Methods}

The study used both qualitative and quantitative techniques and a descriptive survey research design was used. The study was conducted in four leading universities that offer journalism and mass communication training, namely: University of Nairobi, Moi University, Daystar University and United States International University as well as three media houses namely: The Standard Media Group, Royal Media Services and Radio Africa Group. All the four universities offer media and journalism related courses both at the undergraduate and graduate levels.

Simple random sampling, purposive sampling and stratified sampling procedures were used to select the units and the respondents for data collection purposes. The study purposively selected three media houses and four universities training journalism and mass media programmes in the country.

\section{Findings and Discussion}

This section of the paper presents data analysis and interpretation of the research findings. Mugenda (2003) defines data analysis as categorizing, ordering, manipulating and summarizing of data to obtain answers to research questions with its purpose being to reduce data to intelligible and interpretable form so that relation of research problems can be tasted. Research findings are presented in tables supplemented with some discussions.

\section{Student's perception on digital media training}

Digital media continues to evolve at a rapid pace with potential benefits to journalism students. Most students' respondents (80.2\%) reported that there are very few digital media textbooks related to 
digital media in the university library. Furthermore, some of the books that were in the library were irrelevant or complicated. However, a minority $(19.8 \%)$ of student's respondents said the libraries in their universities as well as their departments had enough book materials.

The students respondents also reported that even though their universities had internet connectivity, $48.8 \%$ said internet connection is unreliable while $51.2 \%$ reported that internet connectivity was available and reliable (Table 1). A reliable internet access is critical to students learning and doing their own research on the emerging technologies in the market. Furthermore, most digital media content are transmitted through the internet platform and therefore journalism departments should have a reliable internet connection.

Most student respondents $93 \%$ reported that lecturers do not give them practical assessment examinations, while $7 \%$ reported that they are at times required to do practical project assignments, especially in some courses which require students to freely express their ideas in innovative ways by utilizing digital media technologies. Although most students $52.3 \%$ commented positively toward lecturer's preparation and guidance on the use of technologies, $47.7 \%$ of them said lecturers were prepared and well versed in using some of the digital media technologies. Most students said practical lessons were insufficient. In addition, most students said they had experience in using social media, but expressed inadequacy in their ability to use the technology in a professional capacity and as a medium for producing news.

Despite the fact that some of us are conversant with technical skills on operation of some software and other digital media applications we still require some instruction on using web-based platforms. We require technical skills in the classroom in order to enhance our chances of meeting the demands of the industry which is currently changing and requires technologically savvy graduates who possess an array of multimedia skills.

Additionally, $68.6 \%$ of student respondents said they use some of the digital media tools such as computers, phones, camcorders, internet in a limited way while $18(20.9 \%)$ agreed that the access to such equipment is satisfactory and believed that it will prepare them to keep adapting to the changing media platform. The respondents stated that they preferred using digital media to present their products rather than old technologies and practises.

\section{Lecturers perception on digital media training}

Most respondents $77 \%$ responded that digital media courses are instructed theoretical as per the course syllabi. Only $23 \%$ of the respondents reported that they had been teaching practical digital media courses. The respondents argued that journalism lecturers should focus on teaching theoretical and conceptual knowledge rather than focusing on technical skills.

It is no longer necessary to teach software to students born in the millennial generation who enter college with engrained technical knowledge. Journalism production courses are facing the challenge of teaching technical skills to classes composed of a wide range of abilities and backgrounds using digital tools. In order to overcome the learning

\begin{tabular}{|l|c|c|c|c|}
\hline Factors & \multicolumn{2}{|c|}{ Yes } & \multicolumn{2}{c|}{ No } \\
\hline Lack of relevant digital media books & 59 & $68.6 \%$ & 27 & $31.4 \%$ \\
\hline Insufficient access to internet & 42 & $48.8 \%$ & 44 & $51.2 \%$ \\
\hline $\begin{array}{l}\text { Insufficient preparation and guidance by } \\
\text { lecturers }\end{array}$ & 45 & $52.3 \%$ & 41 & $47.7 \%$ \\
\hline Lack of practical assessment & 80 & $93 \%$ & 6 & $7 \%$ \\
\hline
\end{tabular}

Table 1: Student's perception on digital media training. curve issues, lecturers can offer optional out-of-class workshops. (Lecturer Respondent, University of Nairobi, 18/09/2015).

Respondents argued that developing competency in specific digital media applications should not be the ultimate goal in effective learning because such skills would be obsolete as soon as the application is replaced or upgraded.

Most lecturer respondents $72.2 \%$ reported that lecturers should focus on teaching fundamental principles as a way of preparing the students to use any tools or techniques which may emerge in the future. Some $27.8 \%$ lecturers said that students should be exposed to training on specific applications.

\section{Editors perception on graduate's competence in digital media}

Editors were sampled because they are the immediate managers in a media house who can assess the graduate's competence while working on their assignments. In this connection, $17 \%$ of the respondents reported that journalism graduates have good digital media skills on various online media platforms. Another $33 \%$ of the respondents said most fresh graduates have good skills in the digital media, while $50 \%$ reported that fresh journalism graduates have inadequate skills in working with digital media (Figure 1).

\section{Importance of digital media competence}

The respondents made various observations on the importance of digital media training in relation to competence at work. Ten $(83.3 \%)$ respondents said good digital media skills empower graduates to work with different media platforms. Good competencies in digital media enables journalists to work easily on any medium and consequently a media house would not invest on training journalist on working with various platforms. Two (16.7\%) editors said digital media skills do not add much value to successful execution of work because most of the media houses are still having traditional means of collecting and disseminating news.

Most editors (58.3\%) reported that mastery of digital media skills enhances effectiveness and efficiency in the gathering of news, processing and packaging of information into different media while $41.7 \%$ said graduates who have good training on traditional journalism are good and could be trained in the future on digital media.

Despite the fact that we recognize the importance of digital media skills, we still prefer to employ journalists with good skills on 'traditional media' and then we can train digital skills on our media lab tailored to expose journalist on new technologies, rather than the other way around. (The Standard Media Group Editor, 23/09/2015).

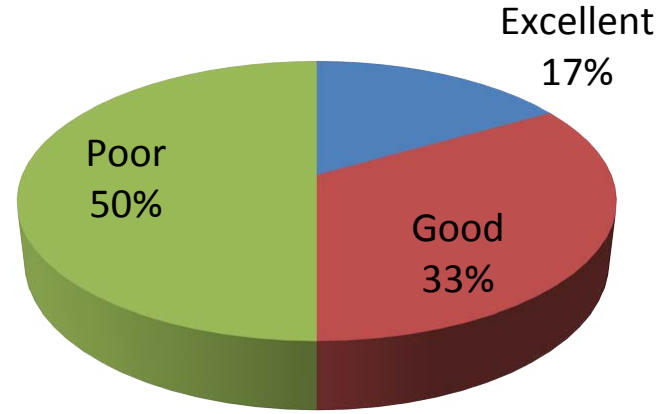

Figure 1: Response on Effectiveness of Digital Media Skills among Journalism Graduates. 


\section{Essential Digital Media skills required in the market}

Respondents were further asked to comment on digital media competencies which are vital for journalists in the current labour market. Five (42\%) respondents said that good skills in convergence and digital media such as multimedia, social media, hypermedia and internet are very important in working in the current media environment.

The respondents agreed that good skills in digital media enable journalists to search for information needed to develop stories quickly. Research and news gathering could be done through search engines, bulletin boards, discussion for a Facebook, or blogs. On the other hand, five $(42 \%)$ other respondents reported with good skills in research, gathering and effective writing skills are prerequisite for successful and effective delivery of functions in the media industry.

Two (16\%) respondents reported that critical thinking and time management skills are important in the current media environment as are valued by editors because journalists can express their thinking in different media. One participant said:

"It is evident that in the newsroom today, we are dealing with more content that is multimedia in nature which necessitates new skills in web content management, different platform adaptability and publishing processes to accommodate new storytelling options such as video, audio, and animation. There is need for journalism schools in the universities to improve their curriculum and training in order to prepare students with the latest digital skills which are important in the media industry." (The Standard Media Group Editor, 28/09/2015).

Other themes emerging from the qualitative data that further seem to support the essential digital media skills required in the market include the need to review journalism curricula in order to address developments in technology and the new media by offering courses that will not only equip students with knowledge and skills on how the digital media is used in their journalistic assignment but also how the new technology is affecting the profession.

\section{Conclusion}

\section{Perception of digital media training}

With respect to the importance of digital media training in relation to competence in journalism profession, the study established that digital media training is essential in giving hands on training to graduates and empowers them with adequate competencies and skills that they can use in the market such as in the process of collecting, processing and packaging news in the right way. In the current digital media environment, there is need for journalism training to emphasize competence in digital media programmes.

Learners need adequate digital media and ICT knowledge, competencies and skills in order to function effectively in collecting, processing and disseminating information. Fresh journalism graduates require adequate orientation in digital technological solutions in order to work effectively and efficiently. The students should be articulate regarding a host of intensive digital media issues involving journalism. Students must be well oriented and prepared not merely in terms of access to technology or to the technical skills, but also to cultural forms of expression and communication. This implies that students need to be educated and trained in new emerging areas of the digital media.

From the study, it can be deduced that digital media training is crucial in imparting relevant competencies and skills essential in the job performance. The current media convergence and digital environment is very challenging that undergraduate journalism students need to be equipped with quality training on these emerging areas.

The study findings are in agreement with those of Frechette [11] who proposed that today's graduates in the market are required to work across a range of multiple platforms and need to have the necessary skills in order to produce output specifically tailored to each of the different digital platforms. The levels of skills needed are beyond that of being a user of technology, but of someone who can work with the technology. This is because the digital media platforms will keep on changing and the key skill will be that of being able to adapt to new changes. Journalists will have to be ready and able to absorb each change.

From the study, it was revealed that journalism programs are too conceptual and spend little time on practical journalistic skills such as online reporting, computer applications, digital editing among other courses. Time spent on theory classes especially in teaching practical oriented courses is not useful for the daily lives of journalists. The finding is in line with the recommendations [12-14] who proposed that journalism training should respond to the needs of the profession. According to Corrigan [13], he states that: "Until journalism professors use their intellectual talents and research efforts to address industry needs better and to prepare future practitioners better, they will continue to endure charges of 'ineptitude' and 'irrelevance'. The study revealed that many courses including those meant to be practical are taught theoretically due to limited resources in the journalism departments. Some department lacks the relevant equipment to facilitate the teaching of practical courses while some universities have more students compared to the available resources.

\section{Essential digital media courses}

The study findings established a number of digital media courses that are essential in the training of journalism undergraduate students in the current digital environment. Digital media training programmes needs to be retailored and integrated with modern technology oriented courses that are quite critical in the modern journalism environment. New emerging communication trends and new media technologies such as advanced multimedia, online and based, web 2.0 technologies, social media, emerging application softwares, networking systems and different digital media hardware have developed in the journalism profession. Digital medium, ICT and new media courses are very important in offering increased job opportunities. Competencies and skills in new media lead to better management and handling of information services.

Journalism has been affected by rapid developments in the modern technological advancement and universities have to respond to these needs and demands of the changing society. The study established measures to address this imbalance that has always affected the information profession in the past through a suitable journalism curriculum. In particular, the curriculum must take into consideration the contemporary issues affecting journalism and training of undergraduate students in relation to globalization and labour market needs. The study suggest that for journalism students to acquire the preferred digital media skills, then the university curriculum must provide digital/new media courses that are relevant to the modern digital environment.

\section{Challenges facing digital media training}

Media and journalism training programmes in Kenyan universities 
have been facing different challenges such as, inadequate digital media curriculum that is affecting the training of undergraduate students. Most of the students are forced to seek additionally training from other fields of study that are technologically-reliant and compliant especially in the departments of information technology and computer science.

Other challenges affecting effective delivery of digital media training include the inadequate computer laboratories in the media departments, few and insufficient digital media equipment, obsolete equipment, inadequate software packages, the lack of relevant digital media courses, the inadequacy of qualified teaching staff, inadequate teaching of digital media courses, some digital media courses that are not in line with market needs, and inadequate infrastructure.

From the study, respondents highlighted the inadequacy of computer laboratories, inadequacy of digital media equipment and the inadequate software packages as the biggest contributing challenge to digital media training. There are some other factors challenging the training of digital media as indicated in literature review.

The sampled universities offer some courses on digital media but there is need for improving these courses. The shortfall in digital media training can also be provided through continuous professional development programmes. Teaching departments in the universities must embrace change so as to cope with the emerging trends in the field of media and journalism. In addition, schools, lecturers, journalists and other stakeholders in the media profession must be proactive in bringing change in training of journalism.

\section{Recommendation}

The rapid changes in the media and journalism landscape necessitate the need to reevaluate and update the undergraduate journalism curriculum so that it reflects the training programmes that match the needs and requirements of the modern media environment as well as enable students acquire the new media knowledge, competencies and skills that is essential in gathering and disseminating news stories.

The media departments should also work continuous to in order to provide a professional development programmes to the students so as to address the market needs. This will also provide the students with the opportunity to grow and acquire the much needed emerging and new competencies and skills in digital media programmes. In addition, the departments should carry out a needs assessment to identify the new emerging media competencies and skills in the labour market.

Transforming undergraduate journalism training in the modern knowledge and learning environment requires continuous professional efforts to revise and update digital media courses. The modern technological revolution fueled by the internet, World Wide Web, web technologies, social media have occasioned the need for journalism departments to review the curriculum and pedagogy so as to enable its graduates learn and acquaint themselves with adequate knowledge and skills to work independently and effectively in the media environment and career development.

\section{References}

1. Burgh $H$ (2003) Skills are not enough: The case for journalism as an academic discipline. Journalism 4: 95-112.

2. Deuze M (2002) National News Cultures: towards a profile of journalists using cross-national survey findings. Journalism Quarterly 79: 134-49.

3. Carpenter D (2010) An Application of the Theory of Expertise. Wenger and Owens.

4. Nyabuga G, Booker N (2013) Mapping Digital Media: Kenya A Report by the Open Society Foundations. Open Society Foundation

5. Hall J (2001) online journalism: a critical primer. London: Pluto Press.

6. Ugangu W (2012) Normative Media Theory and the Rethinking of the Role of the Kenyan Media in a Changing Social Economic Context. Unpublished Doctoral Thesis, University of South Africa.

7. Rogers EM (2003) Diffusion of Innovations. (4th edn.), New York: Free Press.

8. Al-Mobaideen HO (2009) ICT Diffusion in Jordanian Universities. European and Mediterranean Conference on Information Systems, Leeds Metropolitan University. United Kingdom.

9. Berger G, Matras C (2007) Criteria and Indicators for Quality Journalism Training Institutions and Identifying Potential Centres of Excellence in Journalism Training in Africa. UNESCO, Journalism.

10. Houston B (2010) Training Journalists to Use Technological Tools in Reporting. Nieman Reports

11. Frechette $J(2002)$ Developing media literacy in cyberspace: pedagogy and critical learning for the twenty-first-century.

12. Boroff D (2005) What ails the journalism schools. Harper's Magazine.

13. Corrigan D (2003) Journalism academia out of touch. Editor and Publisher.

14. Medsger B (1996) Winds of change: Challenges confronting journalism education. Arlington, VA: Freedom Forum. 